\title{
Hybrid Back-to-Back MMC System for Variable Speed AC Machine Drives
}

\author{
Binbin Li, Junlin $\mathrm{Hu}$, Shaoze Zhou, and Dianguo Xu
}

\begin{abstract}
Modular multilevel converter (MMC) has drawn great attention in variable-speed machine drives. However, a challenge exists that the voltage ripple of sub-module capacitors in MMC would be very large at low motor speed. In this paper, a novel back-to-back (BTB) MMC system is introduced which can effectively limit the capacitor voltage ripple. The grid-side MMC is a hybrid structure which uses full-bridge sub-modules in the upper arm whereas half-bridge sub-modules in the lower arm. The DClink current is controlled to be constant thus the motor-side MMC with half-bridge sub-modules can reduce its DC-link voltage at low frequencies so as to absorb less energy variation and limit the capacitor voltage ripple. The operating principle of this hybrid BTB MMC system and the corresponding control strategies are discussed. The effectiveness has been validated by simulation and experimental results.
\end{abstract}

Index Terms-Back-to-back (BTB) system, capacitor voltage ripple, modular multilevel converter (MMC), sub-module (SM), variable-speed drives.

\section{INTRODUCTION}

$\mathrm{T}$ HE modular multilevel converter (MMC) is the most recent development in the multilevel converter family which was originally proposed for high voltage DC (HVDC) transmission [1], [2]. Meanwhile, MMC has also gained significant research interest in high power motor drive applications due to its advantages such as modularity, scalability, high efficiency, high reliability, and excellent voltage waveform quality [3], [4], and MMC medium-voltage motor drive has already been put into commercial use [5].

However, since the sub-module (SM) capacitors of MMC are floating, the capacitor voltage will fluctuate when arm current flows by. It is revealed that the capacitor voltage ripple of $\mathrm{MMC}$ is directly proportional to the amplitude of the output current while inversely proportional to the output frequency [6]. Hence, this voltage ripple problem would become very severe in the applications where high starting torque is required at low motor speeds. To overcome this problem, measures must be

Manuscript received November 5, 2019; revised March 6, 2020; accepted May 27, 2020. Date of publication June 30, 2020; date of current version June 11, 2020. This work was supported in part by National Natural Science Foundation of China under Grant 51807033 and in part by Science Foundation of Heilongjiang Province under Grant QC2018059.

All authors are with the School of Electrical Engineering and Automation, Harbin Institute of Technology, Harbin 150001, China (e-mail: libinbin@hit. edu.cn; 15395623201@163.com; zhoushaozezsz@foxmail.com; xudiang@hit. edu.cn).

Digital Object Identifier 10.24295/CPSSTPEA.2020.00010 taken to limit the capacitor voltage ripple of MMC within an acceptable range. Injection of a higher frequency circulating current into phase arms, in coordination with a commonmode voltage of the same frequency imposed at the threephase AC terminals, allows the SM capacitors to get charged and discharged more frequently, so as to reduce their voltage ripple [6]-[9]. However, this additional circulating current significantly increases the current rating of the converter, which could be as high as three times that without injection [10]. To reduce the peak value of the injected current, some improved circulating current injection methods using square wave [10][12] and the inclusion of a third-order harmonic [13] were proposed instead of using sinusoidal wave. But the arm current is still much higher than that is required at rated speed. In addition, high magnitudes of harmful common-mode voltage are intentionally superposed upon the motor, which causes bearing current and insulation problems and may shorten the lifetime of the motor. On the other hand, several topology modifications were proposed to address the capacitor voltage ripple problem of MMC. In [14], an additional circuit branch was introduced by a cross-section connection of the upper and lower arms which provides a new power transfer path. In [15], an auxiliary voltage clamping circuit was added in each SM to exchange power with other SMs and force the capacitor voltage stable. The auxiliary balance circuit can also be placed between the adjacent SMs in a dual MMC topology driving an open-end winding machine [16]. In [17], a series switch was added in the DC link of MMC in which the capacitor voltage ripple at low motor speeds is only up to twice the value at rated speed.

Furthermore, in [18], an MMC rectifier is employed as the front end, forming a back-to-back (BTB) MMC system, which has potential for driving four-quadrant motors with energy regenerative capability, such as the pumped hydro storage [19], [20]. The topology, as well as its control strategy, has an advantage that the capacitor voltage ripple can basically keep unchanged, independent of the motor speed. But both the two MMCs are equipped with full-bridge sub-modules (FBSMs). It not only brings great extra hardware cost compared to the half-bridge SM, but also results in higher switching and conduction losses. In [21] the BTB MMC motor drive system is improved, that the half-bridge sub-modules (HBSMs) and FBSMs are employed in a hybrid structure. It inherits the merit of small capacitor voltage ripple of the motor-side MMC at low motor speeds, and more importantly, it remarkably reduces the number of semiconductor devices thus reduces the 


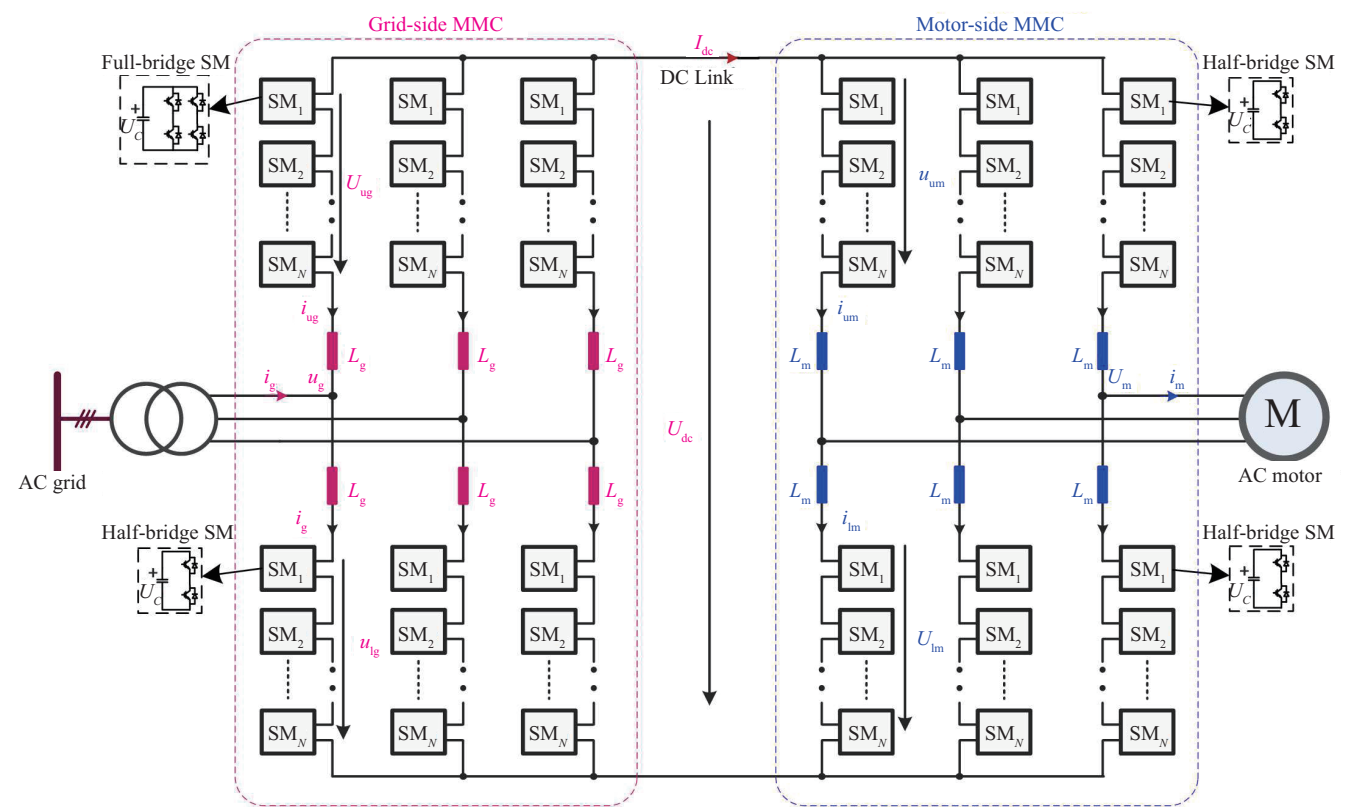

Fig. 1. Circuit configuration of the hybrid BTB MMC motor drive system.

switching and conduction losses and increases the operating efficiency. This paper further extends the work of [21], which systematically presents this approach, mathematically derives the capacitor voltage ripple expressions, improves the control schemes considering decoupling and even distribution of the energy among the phases and between the arms, and builds a lab-scale prototype and is demonstrated with experimental results. The rest of this paper is organized as follows. In Section II, the circuit configuration of the proposed hybrid BTB MMC motor drive system and its operating principle are illustrated. This is followed by the circuit analysis in Section III, which explains why capacitor voltage ripple can be limited at low motor speeds. Further, Section IV discusses the control schemes for this BTB MMC system. The validity of the proposed topology and effectiveness of the control schemes are verified by simulation and experimental results in Section V, respectively. Finally, Section VI concludes this paper.

\section{Circuit Configuration and Operating Principles}

Circuit configuration of the proposed BTB MMC motor drive system is shown in Fig. 1. Two MMCs are connected through the DC side, where one MMC is connected to the grid, named the grid-side MMC, and the other one, named the motor-side MMC, is utilized to drive an AC motor. Each MMC consists of three phases and each phase consists of two arms, the upper and the lower, which are connected through two arm inductors, i.e., $L_{\mathrm{g}}$ in grid-side MMC and $L_{\mathrm{m}}$ in motor-side MMC. And each arm is composed of $N$ series connected SMs.

All the SMs in the motor-side MMC are HBSMs. However, the grid-side MMC has a hybrid structure where the upper arms are made up of FBSMs and the lower arms are composed of HBSMs. The terms $u_{\mathrm{m}}, i_{\mathrm{m}}$ and $u_{\mathrm{g}}, i_{\mathrm{g}}$ represent output AC voltages and currents of the motor-side $\mathrm{MMC}$ and input $\mathrm{AC}$ voltages and currents of grid-side MMC, respectively. $u_{\mathrm{um}}, i_{\mathrm{um}}$ and $u_{\mathrm{lm}}, i_{\mathrm{lm}}$ represent the voltages and currents of the upper arm and the lower arm of the motor-side MMC, respectively. Meanwhile $u_{\mathrm{ug}}, u_{\mathrm{gg}}$ and $i_{\mathrm{ug}}, i_{\mathrm{gg}}$ represent the voltages and currents of the upper arm and the lower arm of the grid-side MMC, respectively. Besides, $U_{\mathrm{dc}}$ is the DC-link voltage and $I_{\mathrm{dc}}$ is the DC-link current.

For the motor-side MMC, the voltages through the upper and lower arms can be represented as

$$
\left\{\begin{array}{l}
u_{\mathrm{um}}=\frac{1}{2} U_{\mathrm{dc}}-u_{\mathrm{m}} \\
u_{\mathrm{lm}}=\frac{1}{2} U_{\mathrm{dc}}+u_{\mathrm{m}}
\end{array} .\right.
$$

The output current $i_{\mathrm{m}}$ splits equally into the upper and lower arms. Incorporating the circulating current component $i_{\text {cir m }}$, currents through the upper and lower arms can be expressed as

$$
\left\{\begin{array}{l}
i_{\mathrm{um}}=i_{\text {cir } \_\mathrm{m}}+\frac{1}{2} i_{\mathrm{m}} \\
i_{\mathrm{lm}}=i_{\text {cir_m }}-\frac{1}{2} i_{\mathrm{m}}
\end{array} .\right.
$$

With even-order harmonics suppressed as described in [22], the circulating current considering only the DC component is

$$
i_{\text {cir_m }}=\frac{1}{3} I_{\mathrm{dc}} \text {. }
$$

The output voltages and currents can be written as

$$
\left\{\begin{array}{l}
u_{\mathrm{m}}=U_{\mathrm{m}} \cos \left(\omega_{\mathrm{m}} t\right) \\
i_{\mathrm{m}}=I_{\mathrm{m}} \cos \left(\omega_{\mathrm{m}} t+\varphi_{\mathrm{m}}\right)
\end{array}\right.
$$




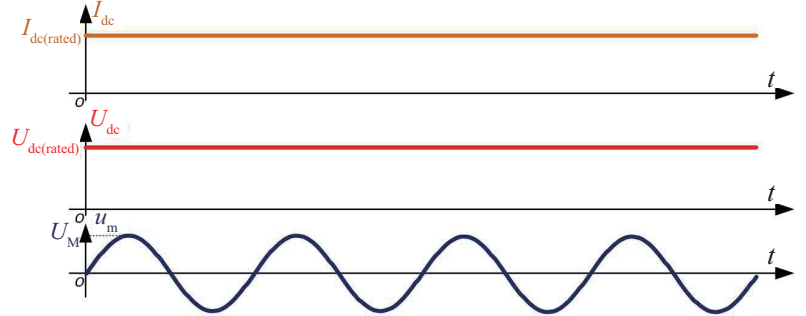

(a)

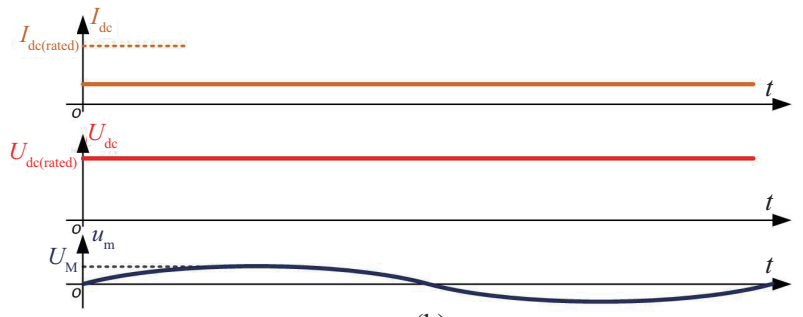

(b)

Fig. 2. Sketch map of operation waveforms of traditional BTB MMC system. (a) At rated speed and (b) under low speed.

where $U_{\mathrm{m}}$ and $I_{\mathrm{m}}$ are magnitudes of the output AC voltage and current, $\varphi_{\mathrm{m}}$ is the phase angle of the motor, and $\omega_{\mathrm{m}}$ is the angular frequency of motor. If the motor is fed to a constant-torque load, $I_{\mathrm{m}}$ is constant. According to pulse width modulation of MMC, $U_{\mathrm{m}}$ can also be written as

$$
U_{\mathrm{m}}=\frac{M}{2} U_{\mathrm{dc}}
$$

in which $M$ presents the modulation index varying from 0 to 1 , and in motor drive applications a constant $U_{\mathrm{m}} / \omega_{\mathrm{m}}$ ratio (i.e., constant Volt/Hertz) is usually ensured.

Conventionally, DC-link voltage of the BTB system is invariant. According to power balance between the AC and DC sides of motor-side MMC (i.e., $1 / 3 U_{\mathrm{dc}} I_{\mathrm{dc}}=1 / 2 U_{\mathrm{m}} I_{\mathrm{m}} \cos \varphi_{\mathrm{m}}$ and converter loss is neglected), the DC-link current $I_{\mathrm{dc}}$ would be in proportion with motor speed when the constant-torque load is applied. Hence, $I_{\mathrm{dc}}$ should be equal to its rated value when the motor operates at rated speed, as shown in Fig. 2(a), whereas $I_{\mathrm{dc}}$ decreases with the reduction of speed, as shown in Fig. 2(b).

In contrast, in terms of the proposed hybrid BTB system, the DC-link current is controlled to be constant as $I_{\mathrm{dc}} \equiv I_{\mathrm{dc}(\mathrm{rated})}$. $U_{\mathrm{dc}}$ is therefore variable which varies in accordance with the motor speed to satisfy the power balance between the AC and DC sides. As shown in Fig. 3, $U_{\mathrm{dc}}$ is equal to $U_{\mathrm{dc}(\mathrm{rated})}$ at rated motor speed whereas decreases linearly under low motor speeds, which follows

$$
U_{\mathrm{dc}}=\frac{\omega_{\mathrm{m}}}{\omega_{\text {rated }}} U_{\mathrm{dc}(\text { rated })}
$$

As a consequence, with the proposed operation mode, when $\omega_{\mathrm{m}}$ varies, the modulation index $M$ in (5) becomes constant so as to satisfy the $U_{\mathrm{m}} / \omega_{\mathrm{m}}$ relationship.

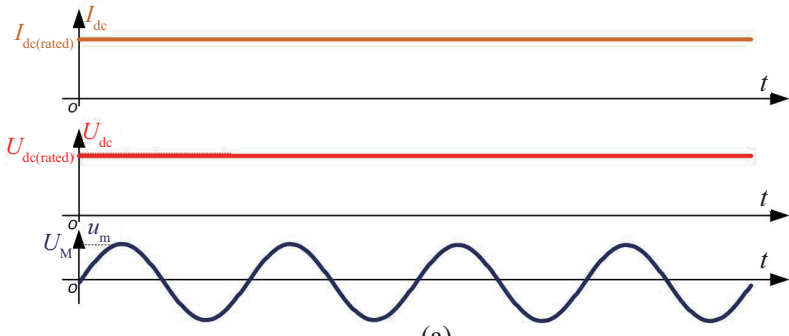

(a)

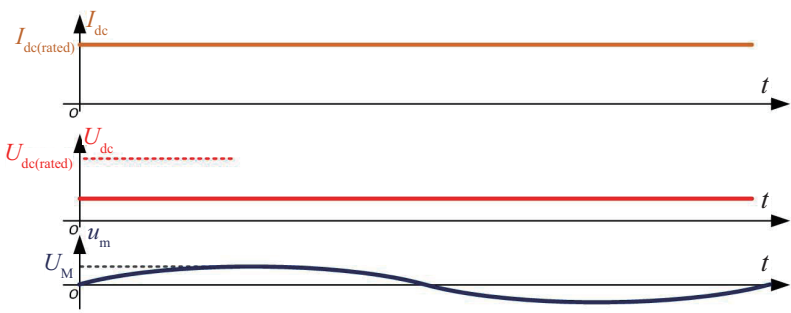

(b)

Fig. 3. Sketch map of operation waveforms of proposed hybrid BTB MMC system. (a) At rated speed and (b) under low speed.

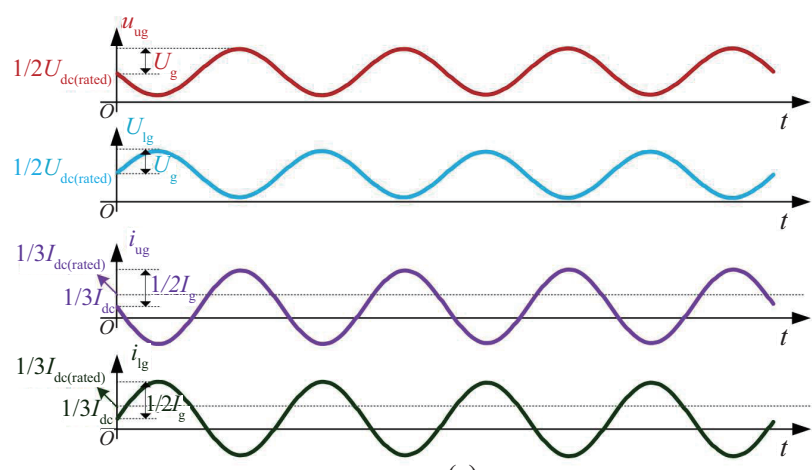

(a)

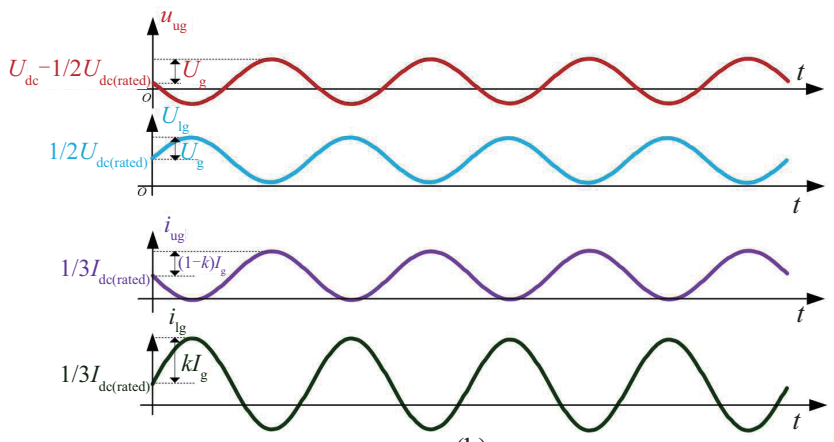

(b)

Fig. 4. Sketch map of operation waveforms in grid-side MMC. (a) Traditional BTB MMC system and (b) proposed hybrid BTB MMC system.

On the other hand, in order to accommodate the variable DC-link voltage, the grid-side MMC is modified by employing FBSMs in the upper arms. Unlike the traditional MMC whose upper and lower arm voltages are symmetrical and presenting the same DC voltage component, i.e., $U_{\mathrm{dc}(\text { rated })} / 2$ as shown in Fig. 4(a), the grid-side MMC in the proposed hybrid BTB 
system has unsymmetrical arm voltages. As shown in Fig. 4(b), DC component of the lower arm voltage is still $U_{\mathrm{dc}(\text { rated })} / 2$, however, by utilizing the voltage reversal capability of FBSMs, DC component of the upper arm voltage is generated as $U_{\mathrm{dc}}-$ $U_{\text {dc(rated) }} / 2$ to make sure summation of the two arms is equal to the variable DC-link voltage $U_{\mathrm{dc}}$. Therefore, the voltages generated by the upper and lower arms in the proposed gridside MMC become

$$
\left\{\begin{array}{l}
u_{\mathrm{ug}}=U_{\mathrm{dc}}-\frac{1}{2} U_{\mathrm{dc}(\text { rated })}-u_{\mathrm{g}} \\
u_{\mathrm{lg}}=\frac{1}{2} U_{\mathrm{dc}(\text { rated })}+u_{\mathrm{g}}
\end{array} .\right.
$$

Due to the unsymmetrical arm voltages, the currents through the upper and lower arms should be unsymmetrical as well so as to keep the power balance of each arm. The AC current therefore would be unevenly distributed between the upper and lower arms, which gives

$$
\left\{\begin{array}{l}
i_{\mathrm{ug}}=i_{\text {cir_g }}-k i_{\mathrm{g}} \\
i_{\mathrm{lg}}=i_{\text {cir_g }}+(1-k) i_{\mathrm{g}}
\end{array},\right.
$$

where a factor $k$ is introduced to denote the AC current distribution ratio between the arms, and $i_{\text {cir } g}$ is the circulating current of grid-side MMC after suppressing the even-order harmonics, which is

$$
i_{\text {cir } \_ \text {g }}=-\frac{1}{3} I_{\mathrm{dc}} \text {. }
$$

The input grid voltages and currents can be written as

$$
\left\{\begin{array}{l}
u_{\mathrm{g}}=U_{\mathrm{g}} \cos \left(\omega_{\mathrm{g}} t\right) \\
i_{\mathrm{g}}=I_{\mathrm{g}} \cos \left(\omega_{\mathrm{g}} t+\varphi_{\mathrm{g}}\right)^{\prime}
\end{array}\right.
$$

where $U_{\mathrm{g}}$ and $I_{\mathrm{g}}$ are the magnitudes of AC voltage and current, $\varphi_{\mathrm{g}}$ is the phase angle of the grid, and $\omega_{\mathrm{g}}$ is angular frequency of the grid. According to power balance between $\mathrm{AC}$ and DC sides (i.e., $1 / 2 U_{\mathrm{g}} I_{\mathrm{g}} \cos \varphi_{\mathrm{g}}=1 / 3 U_{\mathrm{dc}} I_{\mathrm{dc}}$ ), here $I_{\mathrm{g}}$ becomes proportional with the DC-link voltage $U_{\mathrm{dc}}$. Referring to (6), a constant $I_{\mathrm{g}} / \omega_{\mathrm{m}}$ relationship for the grid-side MMC is resulted.

Although DC-link voltage reduces with the decrease of motor speed, the SM capacitor voltages of both MMCs in the proposed BTB system are stable with an average voltage of

$$
U_{C}=\frac{U_{\text {dc(rated) }}}{N}
$$

\section{Sub-Module Capacitor Voltage Ripple Analysis}

To reveal the merits of the proposed hybrid BTB system under low motor speeds, in this section, capacitor voltage ripple of the SMs in the motor-side and grid-side MMCs are analyzed, respectively.

\section{A. Capacitor Voltage Ripple Analysis of the Motor-Side MMC}

Based on (1)-(5), the instantaneous power of the upper and lower arms in the motor-side MMC can be derived as

$$
\left\{\begin{array}{l}
p_{\mathrm{um}}=u_{\mathrm{um}} i_{\mathrm{um}}=\frac{U_{\mathrm{dc}}}{2}\left(1-M \cos \omega_{\mathrm{m}} t\right)\left[\frac{I_{\mathrm{dc}}}{3}+\frac{I_{\mathrm{m}}}{2} \cos \left(\omega_{\mathrm{m}} t+\varphi_{\mathrm{m}}\right)\right] \\
p_{\mathrm{lm}}=u_{\mathrm{lm}} i_{\mathrm{lm}}=\frac{U_{\mathrm{dc}}}{2}\left(1+M \cos \omega_{\mathrm{m}} t\right)\left[\frac{I_{\mathrm{dc}}}{3}-\frac{I_{\mathrm{m}}}{2} \cos \left(\omega_{\mathrm{m}} t+\varphi_{\mathrm{m}}\right)\right]
\end{array}\right.
$$

The instantaneous energy absorbed by the arms are therefore the integral of $p_{\mathrm{um}}$ and $p_{\mathrm{lm}}$, respectively, which gives

$$
\left\{\begin{aligned}
w_{\mathrm{um}}= & \frac{U_{\mathrm{dc}}}{2 \omega_{\mathrm{m}}}\left[\frac{I_{\mathrm{m}}}{2} \sin \left(\omega_{\mathrm{m}} t+\varphi_{\mathrm{m}}\right)-\frac{M I_{\mathrm{dc}}}{3} \sin \left(\omega_{\mathrm{m}} t\right)\right. \\
& \left.-\frac{M I_{\mathrm{m}}}{8} \sin \left(2 \omega_{\mathrm{m}} t+\varphi_{\mathrm{m}}\right)\right] \\
w_{\mathrm{lm}}= & \frac{U_{\mathrm{dc}}}{2 \omega_{\mathrm{m}}}\left[-\frac{I_{\mathrm{m}}}{2} \sin \left(\omega_{\mathrm{m}} t+\varphi_{\mathrm{m}}\right)+\frac{M I_{\mathrm{dc}}}{3} \sin \left(\omega_{\mathrm{m}} t\right)\right. \\
& \left.-\frac{M I_{\mathrm{m}}}{8} \sin \left(2 \omega_{\mathrm{m}} t+\varphi_{\mathrm{m}}\right)\right]
\end{aligned}\right.
$$

The extremum values of $w_{\mathrm{um}}$ and $w_{\mathrm{lm}}$ can be obtained by examining their first derivatives, which actually correspond to the zero values of of $p_{\mathrm{um}}$ and $p_{\mathrm{lm}}$. Since the term $1 \pm M \cos \left(\omega_{\mathrm{m}} t\right)$ in (12) is always larger than zero, the corresponding instants of the extremum values can be solved as

$$
\left\{\begin{array}{l}
t_{\mathrm{um}}=-\varphi_{\mathrm{m}} \pm \arccos \left(-\frac{2 I_{\mathrm{dc}}}{3 I_{\mathrm{m}}}\right) \\
t_{\mathrm{lm}}=-\varphi_{\mathrm{m}} \pm \arccos \left(\frac{2 I_{\mathrm{dc}}}{3 I_{\mathrm{m}}}\right)
\end{array} .\right.
$$

Insertion of (14) into (13), the peak-to-peak value of the energy absorbed by each arm is

$$
\Delta w_{\mathrm{um}}=\Delta w_{\mathrm{lm}}=\frac{2 U_{\mathrm{dc}} I_{\mathrm{dc}}}{3 \omega_{\mathrm{m}} M \cos \varphi_{\mathrm{m}}}\left(1-\frac{M^{2} \cos ^{2} \varphi_{\mathrm{m}}}{4}\right)^{\frac{3}{2}} .
$$

This arm energy variation is eventually buffered by the $N$ SM capacitors in each arm, that is

$$
\Delta w_{\mathrm{um}}=\Delta w_{\mathrm{lm}}=N\left(\frac{1}{2} C U_{\max }^{2}-\frac{1}{2} C U_{\min }^{2}\right)=N C U_{C} \Delta U_{C \mathrm{pp}},
$$

where $\Delta U_{C \mathrm{pp}}$ is the SM capacitor voltage ripple, which is equal to the difference between the maximum and minimum capacitor voltage values $U_{\max }$ and $U_{\min }$. As a result, the SM capacitor voltage ripple in motor-side MMC is

$$
\Delta U_{C \mathrm{pp}}=\frac{2 U_{\mathrm{dc}} I_{\mathrm{dc}}}{3 \omega_{\mathrm{m}} M N C U_{C} \cos \varphi_{\mathrm{m}}}\left(1-\frac{M^{2} \cos ^{2} \varphi_{\mathrm{m}}}{4}\right)^{\frac{3}{2}},
$$


where in conventional MMC, $U_{\mathrm{dc}}$ is invariable and $I_{\mathrm{dc}} / \omega_{\mathrm{m}}$ is constant, but modulation index $M$ would become smaller when the motor speed decreases, which leads to significantly higher capacitor voltage ripple at low motor speeds. In contrast, with the proposed operation mode, $I_{\mathrm{dc}}$ and $M$ are both invariable and $U_{\mathrm{dc}} / \omega_{\mathrm{m}}$ is constant. This means that constant capacitor voltage ripple is ensured within the whole speed range.

It should be noted, practically at speeds very close to zero, the Volt/Hertz relationship of motor would not be satisfied, therefore, the capacitor voltage ripple at very low motor speed will become larger than that of the above theoretical analysis, and it is not possible for the hybrid BTB MMC system to drive a motor stably operating at zero speed with a high torque request, or else some extent of injections [6]-[9] have to be used. However, most medium-voltage motors are not required to operate at zero speed. Due to acceleration of motor, motor speed will quickly surpass the close-to-zero range (and with an asynchronous machine, the slip frequency aspect further relieves this problem), so the hybrid BTB MMC system can be effective to start up a motor.

\section{B. Capacitor Voltage Ripple Analysis of the Grid-Side MMC}

With respect to the grid-side $\mathrm{MMC}$, considering absorbing active power from the grid (i.e., $\cos \varphi_{\mathrm{g}}=-1$ ) and according to (7)-(10), the instantaneous powers of the upper and lower arms can be derived as

$$
\left\{\begin{aligned}
p_{\mathrm{ug}}= & u_{\mathrm{ug}} i_{\mathrm{ug}}=\frac{1}{3}\left[(1-k)-\frac{\omega_{\text {rated }}}{2 \omega_{\mathrm{m}}}\right] U_{\mathrm{dc}} I_{\mathrm{dc}}-\frac{k U_{\mathrm{dc}} I_{\mathrm{dc}}}{3} \cos 2 \omega_{\mathrm{g}} t \\
& -\frac{1}{3} U_{\mathrm{g}} I_{\mathrm{dc}} \cos \omega_{\mathrm{g}} t+\left(\frac{1}{2}-\frac{\omega_{\text {rated }}}{\omega_{\mathrm{m}}}\right) \frac{k U_{\mathrm{dc}}^{2} I_{\mathrm{dc}}}{3 U_{\mathrm{g}}} \cos \omega_{\mathrm{g}} t \\
p_{\mathrm{lg}}= & u_{\mathrm{lg}} i_{\mathrm{lg}}=-\frac{1}{3}\left[(1-k)-\frac{\omega_{\text {rated }}}{2 \omega_{\mathrm{m}}}\right] U_{\mathrm{dc}} I_{\mathrm{dc}}-\frac{(1-k) U_{\mathrm{dc}} I_{\mathrm{dc}}}{3} \cos 2 \omega_{\mathrm{g}} t \\
& +\frac{1}{3} U_{\mathrm{g}} I_{\mathrm{dc}} \cos \omega_{\mathrm{g}} t-\frac{(1-k) \omega_{\mathrm{rated}} U_{\mathrm{dc}}^{2} I_{\mathrm{dc}}}{3 \omega_{\mathrm{m}} U_{\mathrm{g}}} \cos \omega_{\mathrm{g}} t
\end{aligned}\right.
$$

Note that the first term in (18) is a DC component. If $k$ is equal to $1 / 2$ as in conventional MMC where the grid current $i_{\mathrm{g}}$ splits equally into the upper and lower arms, a non-zero DC component would appear in $p_{\text {ug }}$ and $p_{\mathrm{lg}}$. This is unacceptable since a DC power results in continuous charging or discharging of the SM capacitors. Therefore, the DC components in (18) must be zero, which gives

$$
k=1-\frac{\omega_{\text {rated }}}{2 \omega_{\mathrm{m}}}
$$

As a result, the current distribution factor $k$ in the proposed hybrid MMC is dependent on the motor speed.

Expression of the instantaneous arm energy can be derived by performing integration of $p_{\mathrm{ug}}$ and $p_{\mathrm{lg}}$, which gives

$$
\begin{aligned}
w_{\mathrm{ug}}= & {\left[\frac{U_{\mathrm{dc}}^{2} I_{\mathrm{dc}} \omega_{\text {rated }}^{2}}{6 \omega_{\mathrm{m}}^{2} \omega_{\mathrm{g}} U_{\mathrm{g}}}\left(\frac{2 \omega_{\mathrm{m}}}{\omega_{\text {rated }}}-1\right)^{2}-\frac{U_{\mathrm{g}} I_{\mathrm{dc}}}{3 \omega_{\mathrm{g}}}\right] \sin \omega_{\mathrm{g}} t } \\
& -\frac{U_{\mathrm{dc}} I_{\mathrm{dc}} \omega_{\text {rated }}}{12 \omega_{\mathrm{m}} \omega_{\mathrm{g}}}\left(\frac{2 \omega_{\mathrm{m}}}{\omega_{\text {rated }}}-1\right) \sin 2 \omega_{\mathrm{g}} t \\
w_{\mathrm{lg}}= & \left(\frac{U_{\mathrm{g}} I_{\mathrm{dc}}}{3 \omega_{\mathrm{g}}}-\frac{U_{\mathrm{dc}}^{2} I_{\mathrm{dc}} \omega_{\text {rated }}^{2}}{6 \omega_{\mathrm{m}}^{2} \omega_{\mathrm{g}} U_{\mathrm{g}}}\right) \sin \omega_{\mathrm{g}} t \\
& -\frac{U_{\mathrm{dc}} I_{\mathrm{dc}} \omega_{\text {rated }}}{12 \omega_{\mathrm{m}} \omega_{\mathrm{g}}} \sin 2 \omega_{\mathrm{g}} t
\end{aligned}
$$

Likewise, to analyze the SM capacitor voltage ripple of the grid-side MMC, it is necessary to calculate the maximum arm energy variation. Observing (20), it is noteworthy that, within the whole motor speed range $0 \leqslant \omega_{\mathrm{m}} \leqslant \omega_{\text {rated }}$, the amplitude of each term in $w_{\text {ug }}$ is always no higher than the corresponding term in $w_{\mathrm{lg}}$. Hence, for the grid-side MMC, energy variation of the lower arm is more significant. By examining the zero values of (18), the instants corresponding to the extremum values of $w_{\mathrm{lg}}$ can be solved as

$$
t_{\mathrm{lg}}= \pm \arccos \left(-\frac{\omega_{\mathrm{m}} U_{\mathrm{g}}}{\omega_{\text {rated }} U_{\mathrm{dc}}}\right) .
$$

Insertion of (21) into (20) yields the maximum variation of $w_{\mathrm{lg}}$, which is

$$
\Delta w_{\mathrm{lg}}=\frac{I_{\mathrm{dc}}}{3 \omega_{\mathrm{g}}} \sqrt{1-\left(\frac{\omega_{\mathrm{m}} U_{\mathrm{g}}}{\omega_{\text {rated }} U_{\mathrm{dc}}}\right)^{2}}\left|\frac{\omega_{\text {rated }}^{2} U_{\mathrm{dc}}^{2}}{\omega_{\mathrm{m}}^{2} U_{\mathrm{g}}}-U_{\mathrm{g}}\right|
$$

This energy variation has to be buffered by the SM capacitors, referring to (16), the capacitor voltage ripple of grid-side MMC can be obtained as

$$
\Delta U_{C \mathrm{pp}}=\frac{I_{\mathrm{dc}}}{3 \omega_{\mathrm{g}} N C U_{C}} \sqrt{1-\left(\frac{\omega_{\mathrm{m}} U_{\mathrm{g}}}{\omega_{\text {rated }} U_{\mathrm{dc}}}\right)^{2}}\left|\frac{\omega_{\text {rated }}^{2} U_{\mathrm{dc}}^{2}}{\omega_{\mathrm{m}}^{2} U_{\mathrm{g}}}-U_{\mathrm{g}}\right|,
$$

where in the proposed operation mode, $U_{\mathrm{dc}} / \omega_{\mathrm{m}}$ is constant and all the other parameters are invariant, which indicates the capacitor voltage ripple is kept unchanged in the lower arms, irrespective of the motor speed. Moreover, since energy variation of the upper arm is even smaller, the grid-side MMC also presents satisfactory performance in limiting the capacitor voltage ripple.

In comparison with [18] in which all the arms of the two MMCs are employing full-bridge SMs, the proposed BTB system remains the merit that SM capacitor voltage ripples are not increased under low motor speeds. However, the proposed system only uses full-bridge SMs in the upper arms of grid-side MMC while the other arms still utilize half-bridge SMs, which reduces the footprint, capital cost, and conduction losses. 


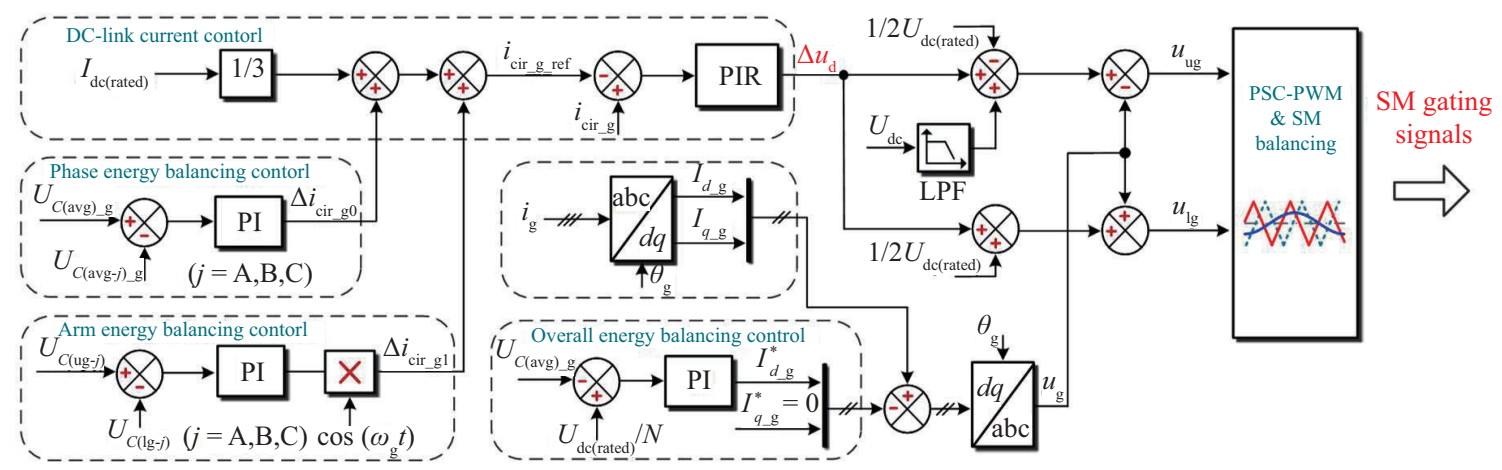

Fig. 5. Control block diagrams of the grid-side MMC.

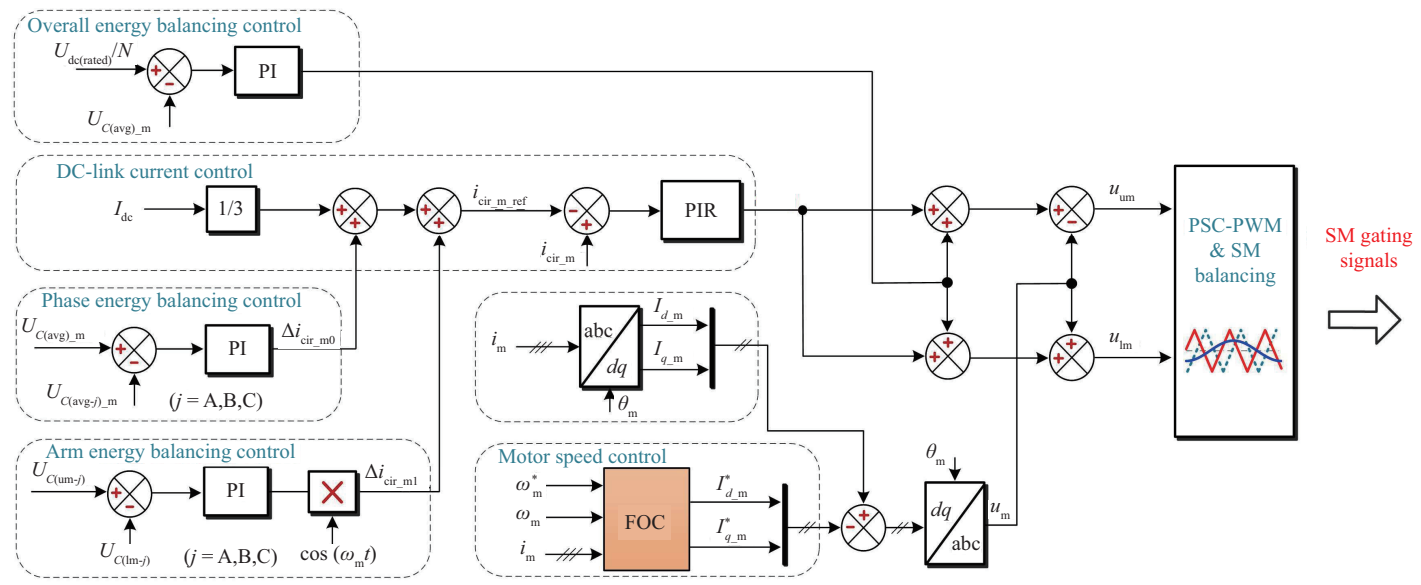

Fig. 6. Control block diagrams of the motor-side MMC.

\section{Control Schemes}

This section develops the suitable control strategies for the proposed hybrid BTB MMC system. The main control targets include regulation of the constant DC-link current, stabilization of the energy stored in the capacitors as well as ensuring its even distribution among the SMs, and the AC current control.

\section{A. Control Strategy of the Grid-Side MMC}

Fig. 5 shows the control strategy of the grid-side MMC. The DC-link current control ensures a constant $I_{\mathrm{dc}}$ by adjusting the DC component in the arm voltages. On the other hand, stable operation of the grid-side MMC requires power balance between AC input and DC output must be maintained. The power difference between the input and output would influence the stored energy in the capacitors, an overall energy balancing control is therefore used to keep the measured average voltage of all the SM capacitors $U_{C(\text { avg }) \text { g }}$ equal to the reference value $U_{\text {dc(rated) }} / N$. This is accomplished by adjusting the absorbed active current command $I_{d \mathrm{~g}}$.

Moreover, a phase energy balancing control is utilized to ensure the total energy are evenly distributed among the three phases. The measured average capacitor voltage of each phase $U_{C(\text { avg-j } j \text { ) }}(j$ represents phase $\mathrm{A}, \mathrm{B}, \mathrm{C}$, respectively) is controlled equal to $U_{C(\text { avg })}$, by producing a DC current adjustment component of the corresponding phase, $\Delta i_{\mathrm{cir}, \mathrm{g} 0}$. Furthermore, The arm energy balance is realized by adjusting a fundamentalfrequency current component $\Delta i_{\text {cir, } 1}$ which automatically keeps the appropriate current distribution factor $k$ as in (19) to stabilize the average capacitor voltage of the upper and lower $\operatorname{arm} U_{C(\mathrm{ug}-\mathrm{j})}$ and $U_{C(\mathrm{~g}-\mathrm{j})}$. Subsequently, these current adjusting components are added with $1 / 3 I_{\mathrm{dc}(\mathrm{rated})}$, which generates the circulating current reference of each phase $i_{\text {cir_g_ref. }}$. An innerloop is then performed to force the actual measured $i_{\text {cir g }}$ follow this reference. A feedforward control is utilized to generate the final arm voltages as in (7), where the actual DC-link voltage $U_{\mathrm{dc}}$ is measured and filtered by a low-pass filter to eliminate the switching harmonics. Finally, the obtained reference voltages are sent to the phase-shifted PWM (PS-PWM) [23], which synthesizes the gating signals for the SM IGBTs and ensures balance of the SM capacitor voltages within each arm.

\section{B. Control Strategy of the Motor-Side MMC}

Control strategy of the motor-side MMC is shown in Fig. 6. Firstly, the field oriented control (FOC) is used to regulate the motor speed and generates the $\mathrm{AC}$ voltage commands. Meanwhile, since the total DC current $I_{\mathrm{dc}}$ is constant in the proposed BTB system, a circulating current controller is employed to force $I_{\mathrm{dc}}$ be evenly distributed among the three phases, giving circulating current of each phase as $1 / 3 I_{\mathrm{dc}}$, where 
TABLE I

Simulation PARAMETERS

\begin{tabular}{|c|c|c|}
\hline & \multicolumn{2}{|c|}{ MMC parameters } \\
\hline & Motor-side & Grid-side \\
\hline Number of SMs per arm & $N=10$ & $N=10$ \\
\hline SM average capacitor voltage & $U_{C}=800 \mathrm{~V}$ & $U_{C}=800 \mathrm{~V}$ \\
\hline Rated DC-link voltage & $U_{\mathrm{dc}(\text { rated })}=8000 \mathrm{~V}$ & $U_{\mathrm{dc}(\text { rated })}=8000 \mathrm{~V}$ \\
\hline SM capacitance & $C=4 \mathrm{mF}$ & $C=4 \mathrm{mF}$ \\
\hline Arm inductance & $L_{\mathrm{m}}=1 \mathrm{mH}$ & $L_{\mathrm{g}}=1 \mathrm{mH}$ \\
\hline Rated output frequency & $f_{\mathrm{m}(\text { rated })}=50 \mathrm{~Hz}$ & $f_{\mathrm{g}}=50 \mathrm{~Hz}$ \\
\hline Rated modulation index & $M=0.85$ & $M=0.85$ \\
\hline Rated AC output current amplitude & $I_{\mathrm{m}}=250 \mathrm{~A}$ & $I_{\mathrm{g}}=250 \mathrm{~A}$ \\
\hline Rated DC-link current & $I_{\mathrm{dc}(\text { rated })}=164 \mathrm{~A}$ & $I_{\text {(rated) }}=164 \mathrm{~A}$ \\
\hline \multirow[t]{2}{*}{ PSC-PWM frequency } & $f_{\mathrm{c}}=1 \mathrm{kHz}$ & $f_{\mathrm{c}}=1 \mathrm{kHz}$ \\
\hline & \multicolumn{2}{|c|}{ Induction machine parameters } \\
\hline Rated power & \multicolumn{2}{|c|}{$S=1.3 \mathrm{MW}$} \\
\hline Number of pole pairs & \multicolumn{2}{|c|}{$p p=10$} \\
\hline Rated speed & \multicolumn{2}{|c|}{$n_{\mathrm{r}}=300 \mathrm{rpm}$} \\
\hline Stator line-line rated voltage amplitude & \multicolumn{2}{|c|}{$U_{1}=4.16 \mathrm{kV}$} \\
\hline Stator line-line rated current amplitude & \multicolumn{2}{|c|}{$I_{1}=250 \mathrm{~A}$} \\
\hline Power factor & \multicolumn{2}{|c|}{$\cos \varphi_{\mathrm{m}}=0.98$} \\
\hline
\end{tabular}

the controlled variable is the DC offset of the arm voltages in each phase.

In order to maintain the overall energy stored in the motorside MMC is stable, the average voltage of all the SM capacitors $U_{C(\mathrm{avg}) \mathrm{m}}$ should be kept equal to the rated voltage $U_{\text {dc(rated) }} / N$. This is realized by adjusting the common-mode DC offset among the three phases, as a result the voltage multiplied with the constant DC current would absorb the appropriate power from the DC side. Besides, the measured average capacitor voltage of each phase $U_{C(\text { avg-j) } \mathrm{m}}$ is controlled equal to $U_{C(\text { avg }) \mathrm{m}}$ by producing a $\mathrm{DC}$ current adjusting component $\Delta i_{\text {cir_m } 0}$ to ensure the phase energy balance. Likewise, arm energy balance is realized by adjusting a fundamentalfrequency current component $\Delta i_{\text {cir_ml }}$. At last, the PSC-PWM is adopted to generate the gating signals for the SM IGBTs.

\section{Simulation and Experimental Results}

\section{A. Simulation Results}

To verify the validity of the proposed hybrid BTB MMC drive system and its corresponding control strategies, a 1.3 MW BTB MMC is simulated based on MATLAB/Simulink, where a constant-torque load $\left(I_{\mathrm{m}}=250 \mathrm{~A}\right)$ is connected. For both MMCs, the rated DC-link voltage is set as $8 \mathrm{kV}$ provided by $10 \mathrm{SMs}$ in each arm with a rated voltage of $800 \mathrm{~V}$. Detailed parameters of the simulation are listed in Table I.

Fig. 7 records the simulation results of the motor-side MMC under different motor frequencies. In Fig. 7(a), the motor frequency was at rated $50 \mathrm{~Hz}$. The output AC currents were regulated at amplitude of $250 \mathrm{~A}$. The DC-link voltage $U_{\mathrm{dc}}$ was $8 \mathrm{kV}$, the DC-link current $I_{\mathrm{dc}}$ was $164 \mathrm{~A}$, and the upper-and lower-arm SM capacitor voltage ripples were $72 \mathrm{~V}$.

In Fig. 7(b) and (c), the motor frequency has been reduced to $25 \mathrm{~Hz}$ and $5 \mathrm{~Hz}$, respectively. It can be noticed that both the AC currents and the DC-link current $I_{\mathrm{dc}}$ were invariant, whereas the DC-link voltage $U_{\mathrm{dc}}$ decreased in proportion with the motor frequency to maintain constant $U_{\mathrm{dc}} / \omega_{\mathrm{m}}$. The capacitor voltage ripples were basically kept constant irrespective of the motor frequency and which agrees well with the theoretical analysis in (17).

On the other hand, Fig. 8 shows the simulation results of the grid-side MMC under different motor frequencies. The condition of $50 \mathrm{~Hz}$ motor frequency is shown in Fig. 8(a). It can be observed that capacitor voltage ripple of both the upperand lower-arm SM were $72 \mathrm{~V}$. The grid currents were with 250 A amplitude and in phase with the grid voltages which ensures an unit power factor. The DC components of arm voltages $u_{\mathrm{ug}}$ and $u_{\mathrm{gg}}$ were $4 \mathrm{kV}$ and the DC components of arm currents $i_{\mathrm{ug}}$ and $i_{\mathrm{lg}}$ were $55 \mathrm{~A}$. The AC components of $i_{\mathrm{ug}}$ and $i_{\mathrm{lg}}$ were equal to $125 \mathrm{~A}$ which is consistent with the distribution factor $k=0.5$ in (8) and (19).

Fig. 8(b) and (c) show the conditions of $25 \mathrm{~Hz}$ and $5 \mathrm{~Hz}$ motor speed, respectively. When motor speeds decreased, the power consumed by the motor was decreased as well. As a result, it can be seen the amplitudes of grid currents decreased with the reduction of speed to keep power balance of the whole system. Besides, DC component of $u_{\mathrm{ug}}$ (with full-bridge SMs) was $0 \mathrm{kV}$ at $25 \mathrm{~Hz}$ and $-3.2 \mathrm{kV}$ at $5 \mathrm{~Hz}$, whereas DC component of $u_{\mathrm{lg}}$ (with half-bridge SMs) was kept constant at $4 \mathrm{kV}$. The arm currents $i_{\mathrm{ug}}$ and $i_{\mathrm{gg}}$ became unsymmetrical with different AC current components distribution $\left(i_{\text {ug }}: 0\right.$ A at $25 \mathrm{~Hz}$ and $95 \mathrm{~A}$ at $5 \mathrm{~Hz}$ and $i_{\mathrm{lg}}: 135 \mathrm{~A}$ at $25 \mathrm{~Hz}$ and $130 \mathrm{~A}$ at $5 \mathrm{~Hz}$ ). These results also follow (8) and (19). Particularly, it can be 

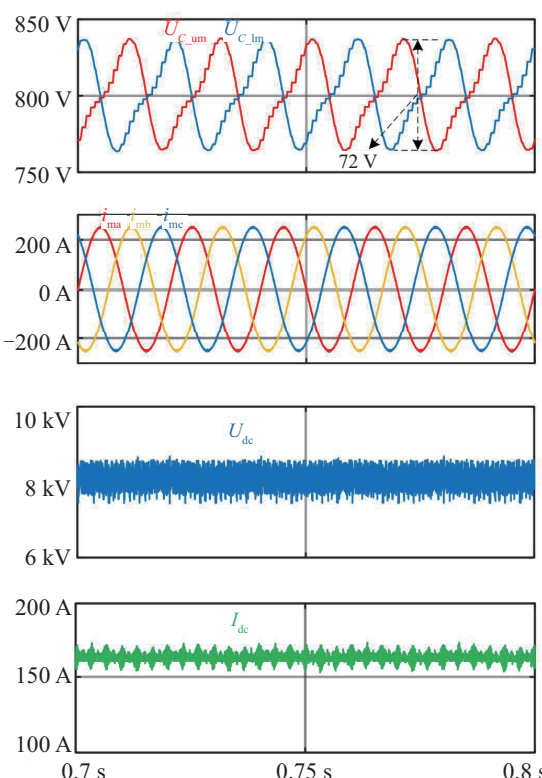

(a)
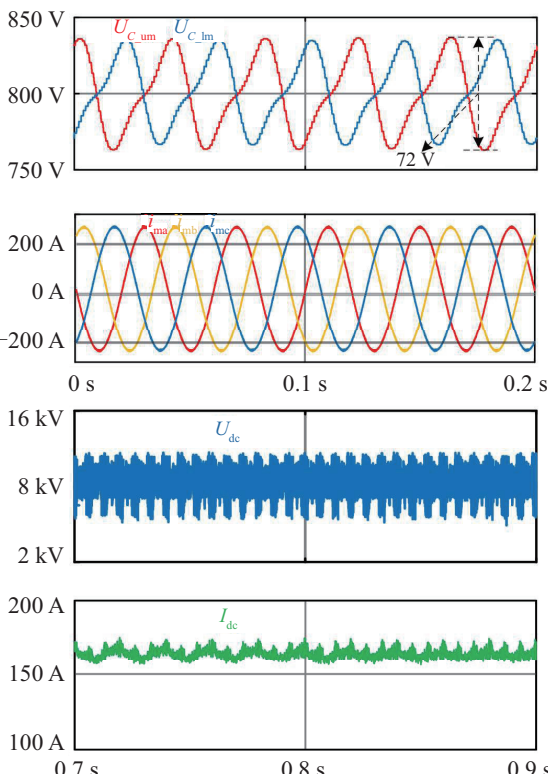

(b)
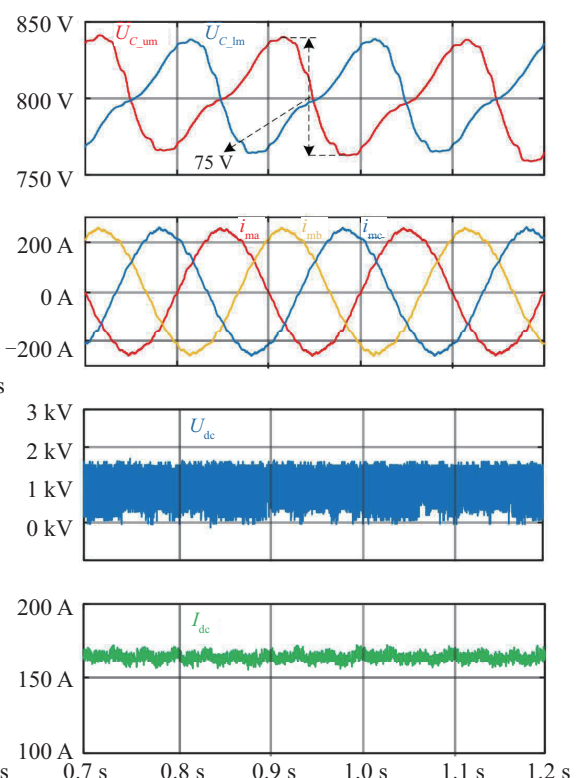

(c)

Fig. 7. Simulation results of motor-side MMC when operating at $50 \mathrm{~Hz}, 25 \mathrm{~Hz}, 5 \mathrm{~Hz}$, respectively.

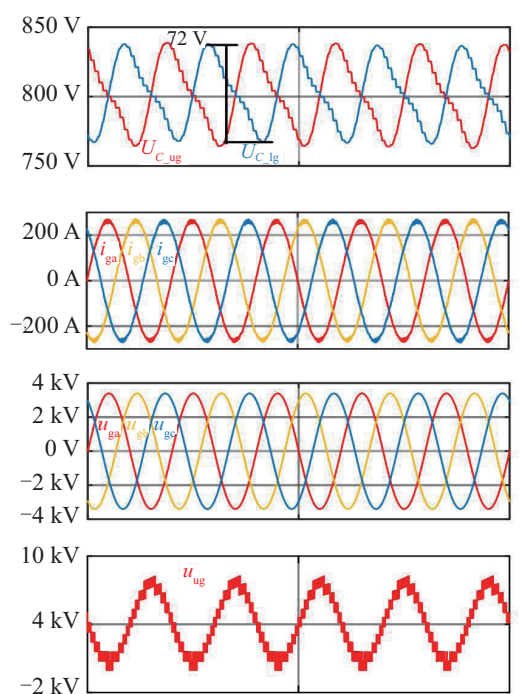

$10 \mathrm{kV}$
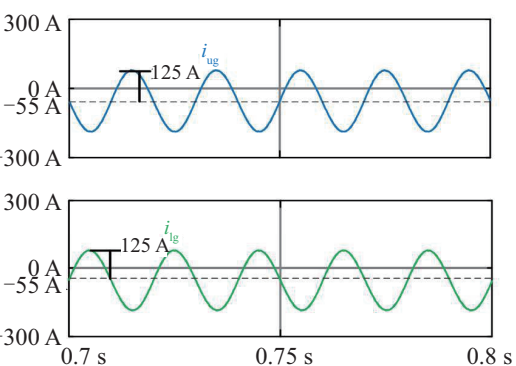

(a)

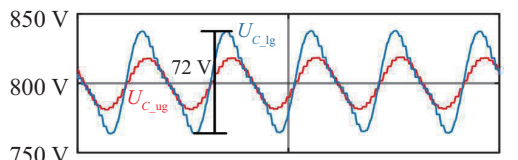

$200 \mathrm{~A}$

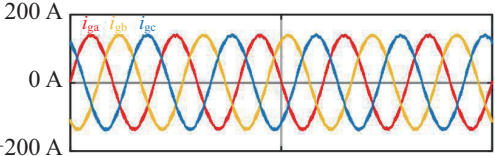

$4 \mathrm{kV}$

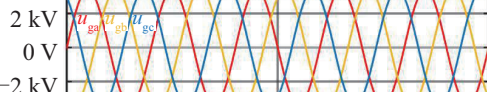

$-2 \mathrm{kV} H \mathrm{~kg}, \mathrm{GO}$

$4 \mathrm{kV}$

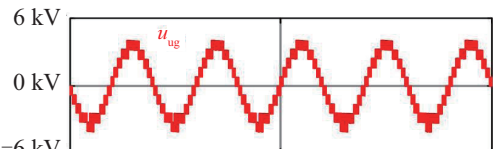

$-6 \mathrm{kV}$

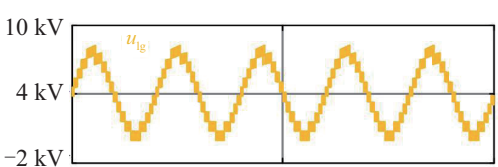

300
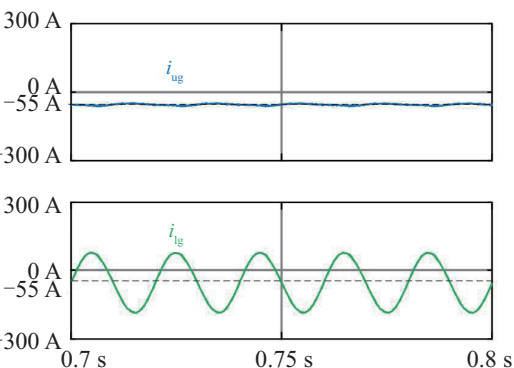

(b)
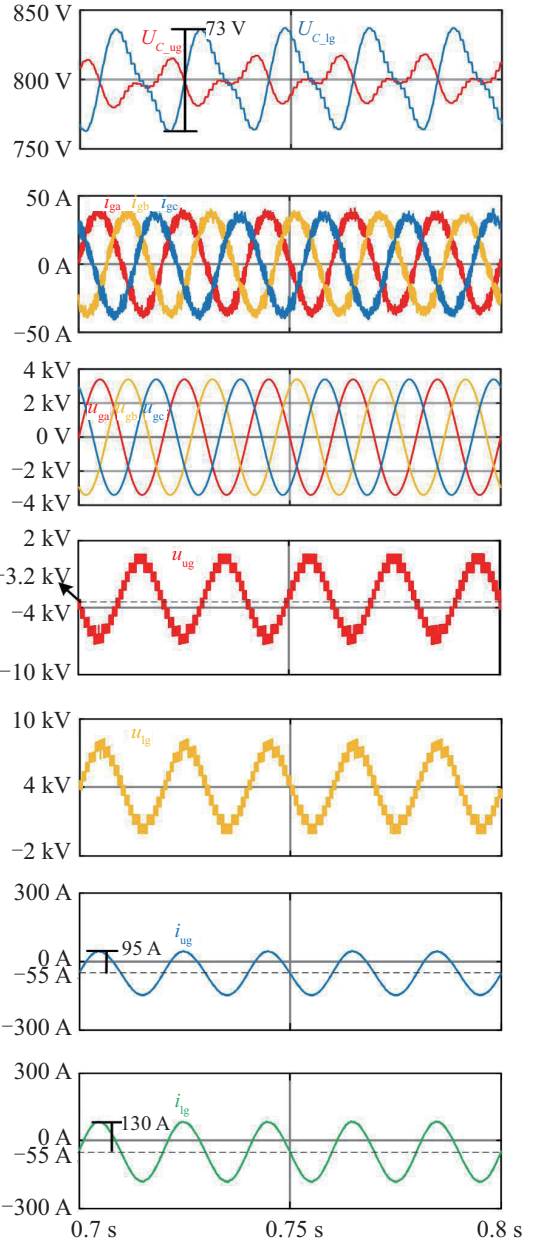

(c)

Fig. 8. Simulation results of grid-side MMC when operating at $50 \mathrm{~Hz}, 25 \mathrm{~Hz}, 5 \mathrm{~Hz}$, respectively. 
TABLE II

Theoretical and Simulated Capacitor Voltage Ripples in Motor-Side and Grid-Side MMCS

\begin{tabular}{lccccc}
\hline \hline \multirow{2}{*}{ Frequency/Hz } & \multicolumn{2}{c}{ Simulation ripple/V } & & \multicolumn{2}{c}{ Simulation ripple/V } \\
\cline { 2 - 3 } & Motor-side MMC & Grid-side MMC & & Motor-side MMC & Grid-side MMC \\
\hline 50 & 72 & 72 & 78.5 & 75.9 \\
25 & 72 & 73 & 78.5 & 75.9 \\
5 & 75 & 72 & 78.5 & 75.9 \\
\hline \hline
\end{tabular}

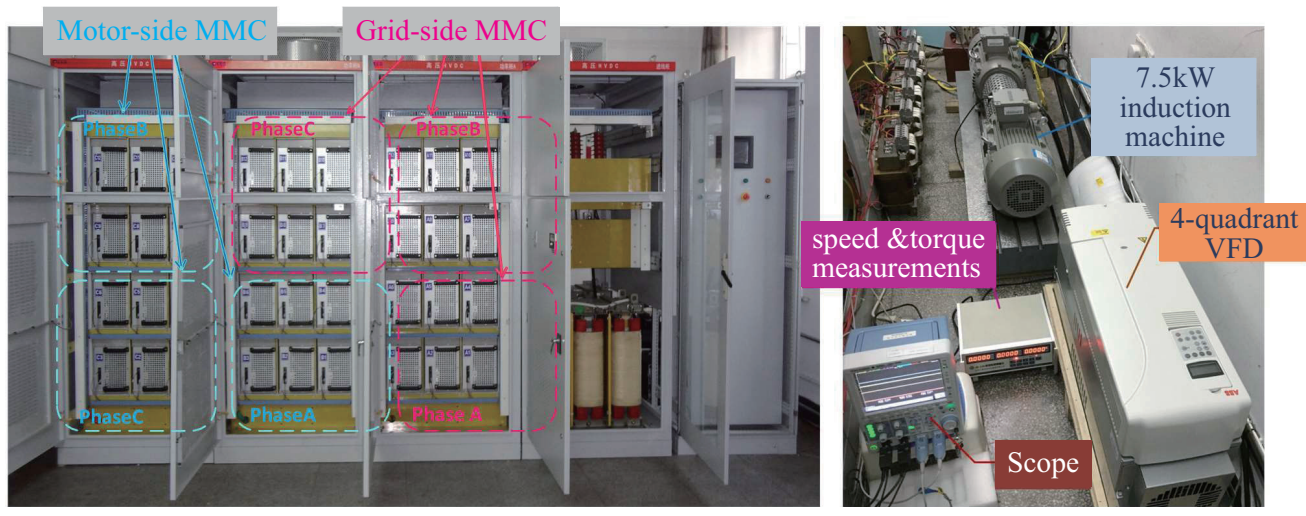

Fig. 9. BTB MMC motor-drive platform.

seen that capacitor voltage ripple of the lower arm $U_{C \text { lg }}$ was kept unchanged, whereas capacitor voltage ripple of the upper arm was always no higher than that of the lower. Furthermore, Table II illustrates that the simulated capacitor voltage ripple of both the motor-side and grid-side MMC coincide with the theoretical values. These results confirm that the capacitor voltage ripple at low motor speeds has been well limited in both the motor-side and grid-side MMCs.

\section{B. Experimental Results}

The proposed hybrid BTB MMC drive system is further verified by building a scaled-down prototype with two induction motors (Siemens 1LE0001-1CB23-3AA4) as shown in Fig. 9. One motor is driven by a four-quadrant commercial drive (ABB ASC800-1 1-0016-3) providing a constant torque load and the other is driven by the hybrid BTB MMC. Detailed parameters of the experimental platform are listed in Table III.

Fig. 10(a) presents the experimental results at $50 \mathrm{~Hz}$. Amplitude of AC output current of the motor-side MMC was $22 \mathrm{~A}$. The grid voltage $u_{\mathrm{g}}$ and current $i_{\mathrm{g}}$ were basically in the same phase angle which represents high power factor. The DC-link voltage $U_{\mathrm{dc}}$ was at rated voltage $750 \mathrm{~V}$ and the DC-link current $I_{\mathrm{dc}}$ was regulated at $11.5 \mathrm{~A}$. The average capacitor voltages of SMs in both sides were maintained balanced $U_{\text {dc(rated })} / N=250 \mathrm{~V}$. The capacitor voltage ripples of motor-side MMC were $18.4 \mathrm{~V}$ and that of the grid-side MMC were $13.4 \mathrm{~V}$.

Fig. 10(b) further represents the experimental results at $25 \mathrm{~Hz}$. Amplitude of AC output current of the motor-side MMC was still 22 A which shows constant torque characteristic. Meanwhile, amplitude of the grid current was reduced accordingly which maintains the power balance of the whole system. The DC-link voltage $U_{\mathrm{dc}}$ was reduced to $385 \mathrm{~V}$ and DC-link current $I_{\mathrm{dc}}$ was still 11.5 A. The capacitor voltage ripples of the motor-side MMC were kept at $18.4 \mathrm{~V}$. Capacitor voltage ripple of the lower arm of grid-side MMC $U_{C_{-} \text {lg }}$ was constant at $13.4 \mathrm{~V}$, whereas voltage ripple of the upper arm $U_{C_{-} \text {ug }}$ became smaller than $U_{C_{-} \mathrm{g} g}$.

Experimental results of $5 \mathrm{~Hz}$ and $2 \mathrm{~Hz}$ motor frequencies are further shown in Fig. 10(c) and (d). The grid current amplitude was even smaller, the DC-link voltage $U_{\mathrm{dc}}$ was further reduced, while the DC-link current $I_{\mathrm{dc}}$ was invariant. Capacitor voltage ripples of the grid-side $\mathrm{MMC}$ were stable, but capacitor voltage ripples of motor-side MMC were increased higher than the theoretical value. This is mainly due to the practically higher $U_{\mathrm{dc}}$ at low motor speeds. which has to ensure $1 / 2 U_{\mathrm{dc}}$ is higher than $u_{\mathrm{m}}$ and also compensates the non-linearity of $\mathrm{V} /$ $F$ relationship of the induction motor and the corresponding IGBT voltage drops. This effect is more significant in the downscaled prototype since the voltage drops across the IGBT and parasitic resistances are not as negligible as in the practical motor drive with rating of tens of $\mathrm{kV}$. But this capacitor voltage ripple at very low speed is still acceptable which is much smaller when compared to conventional MMC.

Fig. 11 shows the experimental waveforms of the motor acceleration performance. The motor accelerated from $0 \mathrm{rpm}$ to $1460 \mathrm{rpm}$ within 7.2 seconds with load torque keeping constant. The magnitude of motor-side AC current $i_{\mathrm{m}}$ kept $22 \mathrm{~A}$. The $I_{\mathrm{dc}}$ was constant at $11.5 \mathrm{~A}, U_{\mathrm{dc}}$ and grid current $i_{\mathrm{g}}$ increased with the increase of speed. It is clear from Fig. 11 that the dynamic waveforms were smooth with little overshoot, and the 
TABLE III

EXPERIMENT PARAMETERS

\begin{tabular}{lcc}
\hline \hline & \multicolumn{2}{c}{ MMC parameters } \\
\cline { 2 - 3 } & Motor-side & Grid-side \\
\hline Number of SMs per arm & $N=3$ & $N=3$ \\
SM average capacitor voltage & $U_{C}=250 \mathrm{~V}$ & $U_{C}=250 \mathrm{~V}$ \\
Rated DC-link voltage & $U_{\mathrm{dc}(\text { rated })}=750 \mathrm{~V}$ & $U_{\mathrm{dc}(\text { rated })}=750 \mathrm{~V}$ \\
SM capacitance & $C=1.86 \mathrm{mF}$ & $C=1.86 \mathrm{mF}$ \\
Arm inductance & $L_{\mathrm{m}}=2 \mathrm{mH}$ & $L_{\mathrm{g}}=2 \mathrm{mH}$ \\
Rated output frequency & $f_{\mathrm{m}(\text { (rated })}=50 \mathrm{~Hz}$ & $f_{\mathrm{g}}=50 \mathrm{~Hz}$ \\
Rated modulation index & $M=0.83$ & $M=0.83$ \\
Rated AC output current amplitude & $I_{\mathrm{m}}=20 \mathrm{~A}$ & $I_{\mathrm{g}}=22 \mathrm{~A}$ \\
Rated DC-link current & $I_{\mathrm{dc}(\text { (rated) }}=11.5 \mathrm{~A}$ & $I_{\mathrm{dc}(\text { rated })}=11.5 \mathrm{~A}$ \\
PSC-PWM frequency & $f_{\mathrm{c}}=3 \mathrm{kHz}$ & $f_{\mathrm{c}}=3 \mathrm{kHz}$ \\
SM IGBT FF300R17KE3 & $1700 \mathrm{~V} / 300 \mathrm{~A}$ & $1700 \mathrm{~V} / 300 \mathrm{~A}$ \\
\hline & \multicolumn{2}{c}{ Induction machine parameters } \\
\hline Rated power & \multicolumn{2}{c}{$S=7.5 \mathrm{~kW}$} \\
Number of pole pairs & \multicolumn{2}{c}{$p p=2$} \\
Rated speed & \multicolumn{2}{c}{$n_{\mathrm{r}}=1460 \mathrm{rpm}$} \\
Stator line-line rated rms voltage & \multicolumn{2}{c}{$U_{1}=380 \mathrm{~V}$} \\
Stator line-line rated rms current & \multicolumn{2}{c}{$I_{1}=15.7 \mathrm{~A}$} \\
Power factor & \multicolumn{2}{c}{$\cos \varphi_{\mathrm{m}}=0.82$} \\
\hline \hline
\end{tabular}

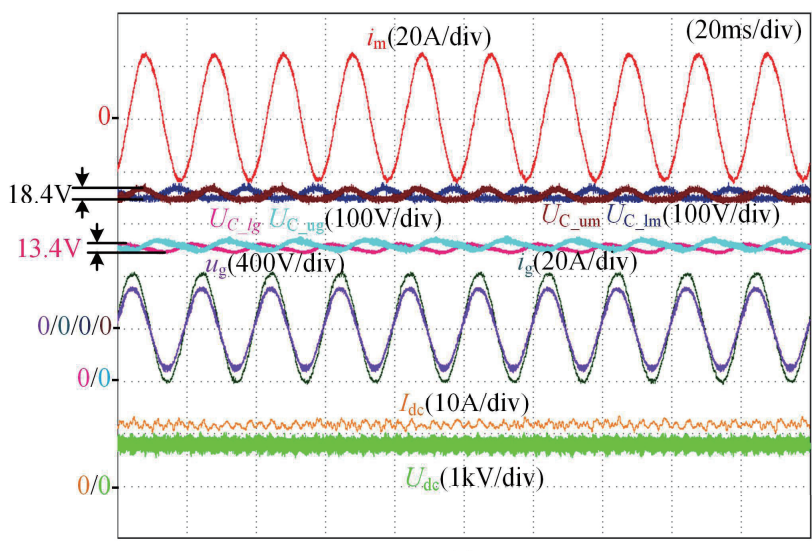

(a)

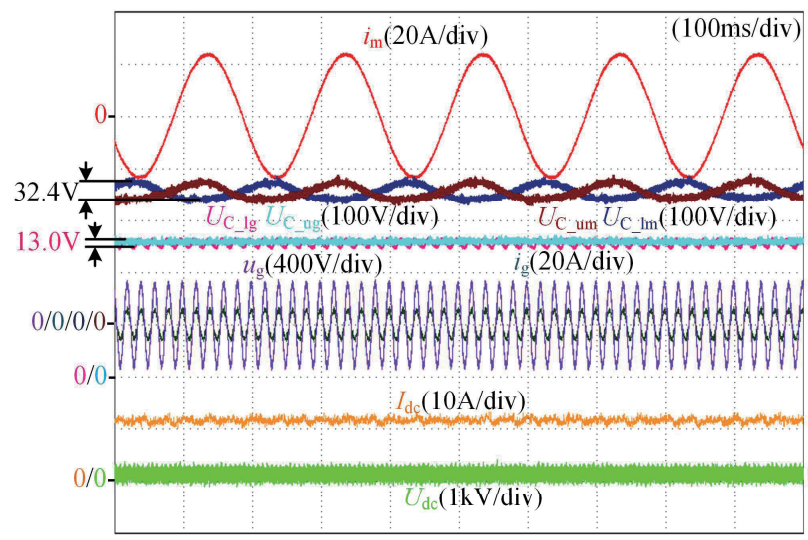

(c)

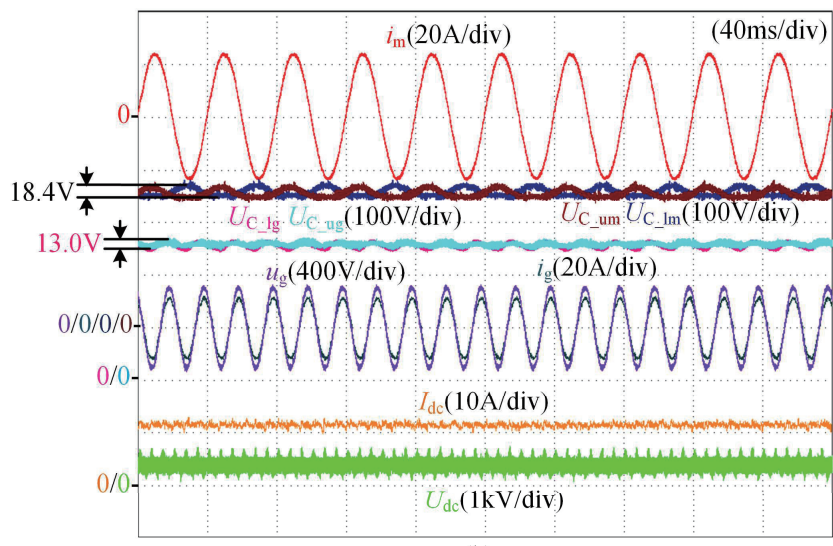

(b)

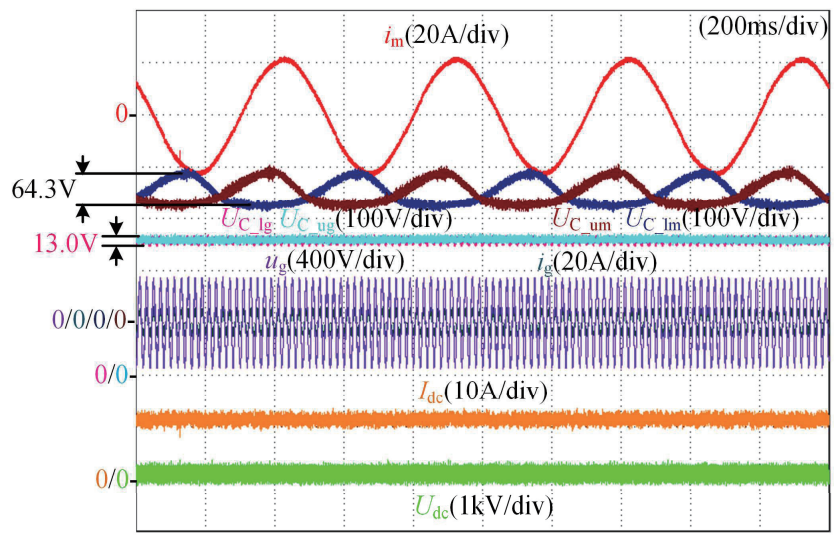

(d)

Fig. 10. Experimental results of grid-side $\mathrm{MMC}$ when operating at $50 \mathrm{~Hz}, 25 \mathrm{~Hz}, 5 \mathrm{~Hz}, 2 \mathrm{~Hz}$, respectively. 


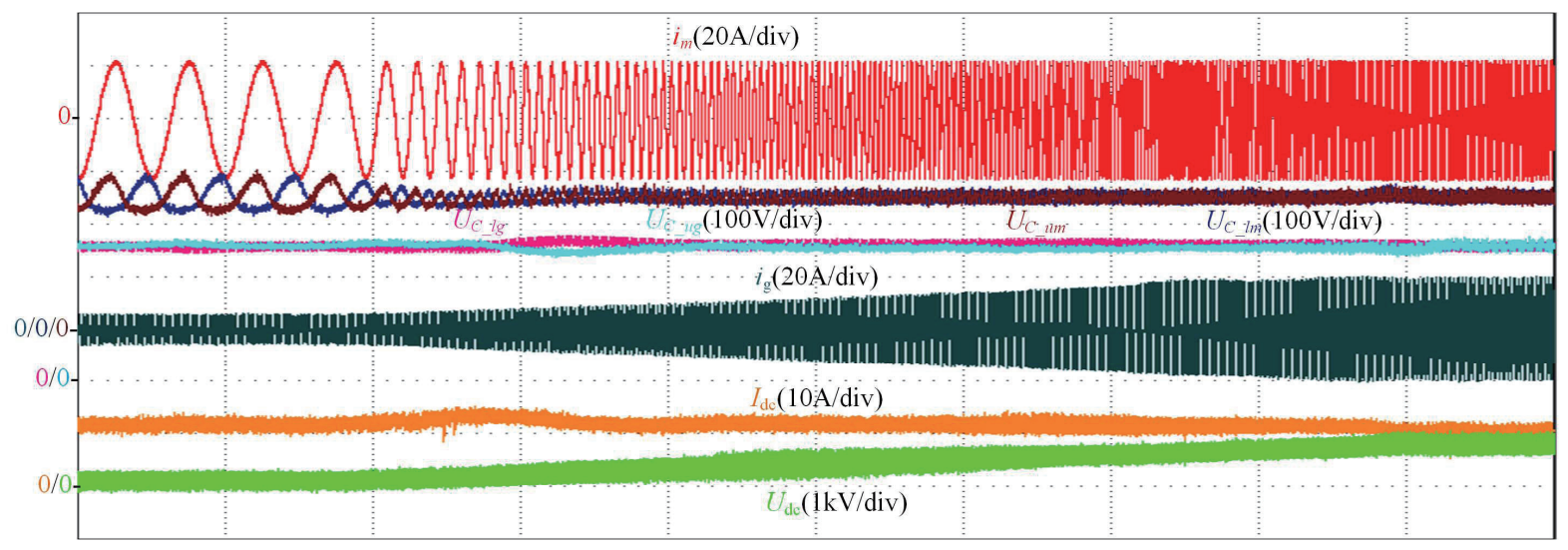

Fig. 11. Experimental results when motor accelerates from $2 \mathrm{~Hz}$ to $50 \mathrm{~Hz}$.

maximum capacitor voltage ripple was limited less than $70 \mathrm{~V}$ (28\% peak-to-peak) throughout the whole speed range.

\section{Conclusion}

This paper proposes a novel hybrid BTB MMC topology and the corresponding control method to solve the problem of large sub-module capacitor voltage ripple. The grid-side MMC is composed of FBSMs in the upper arms and HBSMs in the lower arms, which is controlled to provide constant DC current to the motor-side MMC with only HBSMs. Compared to previous work in which all the arms of the two MMCs were employing full-bridge SMs, the proposed BTB system remains the merit that SM capacitor voltage ripples are not increased under low motor speeds. Moreover, the number of semiconductor devices as well as the losses are reduced. Operating principle and control strategies for this hybrid BTB MMC system were discussed. The validity and effectiveness were confirmed by simulation and experimental results.

\section{REFERENCES}

[1] A. Lesnicar and R. Marquardt, "An innovative modular multilevel converter topology suitable for a wide power range," in Proceedings of IEEE Power Tech Conference, Bologna, Italy, vol. 3, Jun. 23-26, 2003.

[2] S. Kouro, M. Malinowski, K. Gopakumar, J. Pou, L. G. Franquelo, B. Wu, J. Rodriguez, M. A. Perez, and J. I. Leon, "Recent advances and industrial applications of multilevel converters," in IEEE Transactions on Industrial Electronics, vol. 57, no. 8, pp. 2553-2580, Aug. 2010.

[3] M. A. Perez, S. Bernet, J. Rodriguez, S. Kouro, and R. Lizana, "Circuit topologies, modeling, control schemes, and applications of modular multilevel converters," in IEEE Transactions on Power Electronics, vol. 30, no. 1, pp. 4-17, Jan. 2015.

[4] H. Akagi, "Multilevel converters: fundamental circuits and systems," in Proceedings of the IEEE, vol. 105, no. 11, pp. 2048-2065, Nov. 2017.

[5] SIEMENS, Sinamics Perfect Harmony GH 150 Drives. [Online]. Available:http://www.siemens.com/sinamics-perfect-harmony-gh150.

[6] A. J. Korn, M. Winkelnkemper, and P. Steimer, "Low output frequency operation of the modular multi-level converter", in Proceedings of 2010 IEEE Energy Conversion Congress and Exposition, Atlanta, GA, 2010, pp. 3993-3997.

[7] M. Spichartz, V. Staudt, and A. Steimel, "Modular multilevel converter for propulsion system of electric ships," in Proceedings of 2013 IEEE Electric Ship Technologies Symposium (ESTS), Arlington, VA, 2013, pp. 237-242.

[8] K. Wang, Y. Li, Z. Zheng, and L. Xu, "Voltage balancing and fluctuation- suppression method of floating capacitors in a new modular multilevel converter," in IEEE Transactions on Industrial Electronics, vol. 60, no. 5, pp. 1943-1954, May 2013.

[9] A. Antonopoulos, L. Angquist, S. Norrga, K. Ilves, L. Harnefors, H.P. Nee, "Modular multilevel converter AC motor drives with constant torque from zero to nominal speed," in IEEE Transactions on Industry Applications, vol. 50, no. 3, pp. 1982-1993, May-Jun. 2014.

[10] M. Hagiwara, I. Hasegawa, and H. Akagi, "Start-up and low-speed operation of an electric motor driven by a modular multilevel cascade inverter," in IEEE Transactions on Industry Applications, vol. 49, no. 4, pp. 1556-1565, Jul.-Aug. 2013.

[11] J. Jung, H. Lee, and S.-K. Sul, "Control strategy for improved dynamic performance of variable-speed drives with modular multilevel converter," in IEEE Journal of Emerging and Selected Topics in Power Electronics, vol. 3, no. 2, pp. 371-380, Jun. 2015.

[12] B. Li, S. Zhou, D. Xu, R. Yang, D. Xu, C. Buccella, and C. Cecati, “An improved circulating current injection method for modular multilevel converters in variable-speed drives" in IEEE Transactions on Industrial Electronics, vol. 63, no. 11, pp. 7215-7225, Nov. 2016.

[13] S. Debnath, J. Qin, and M. Saeedifard, "Control and stability analysis of modular multilevel converter under low-frequency operation," in IEEE Transactions on Industrial Electronics, vol. 62, no. 9, pp. 5329-5339, Sep. 2015.

[14] S. Du, B. Wu, K. Tian, N. Zargari, and Z. Cheng, "An active crossconnected modular multilevel converter (AC-MMC) for mediumvoltage motor drive," in IEEE Transactions on Industrial Electronics, vol. 63, no. 8, pp. 4707-4717, Aug. 2016.

[15] X. Wang, Q. Ge, Z. Chu, Y. Luo, Z. Sun, Y. Li, and X. Lv, "A novel modular multilevel converter topology with auxiliary voltage clamping circuit for high voltage motor drive", in Proceedings of 2014 9th IEEE Conference on Industrial Electronics and Applications, Hangzhou, 2014, pp. 1392-1397.

[16] M. S. Diab, A. M. Massoud, S. Ahmed and B. W. Williams, "A dual modular multilevel converter with high-frequency magnetic links between submodules for MV open-end stator winding machine drives," in IEEE Transactions on Power Electronics, vol. 33, no. 6, pp. 51425159, Jun. 2018.

[17] B. Li, S. Zhou, D. Xu, S. J. Finney, and B. W. Williams, "A hybrid modular multilevel converter for medium-voltage variable-speed motor drives," in IEEE Transactions on Power Electronics, vol. 32, no. 6, pp. 4619-4630, Jun. 2017.

[18] Y. S. Kumar and G. Poddar, "Control of medium-voltage AC motor drive for wide speed range using modular multilevel converter," in IEEE Transactions on Industrial Electronics, vol. 64, no. 4, pp. 2742-2749, Apr. 2017.

[19] P. K. Steimer, O. Senturk, S. Aubert, and S. Linder, "Converter-fed synchronous machine for pumped hydro storage plants," in Proceedings of 2014 IEEE Energy Conversion Congress and Exposition (ECCE), Pittsburgh, PA, 2014, pp. 4561-4567. 
[20] M. Espinoza, R. Cárdenas, M. Díaz, A. Mora, and D. Soto, "Modelling and control of the modular multilevel converter in back to back configuration for high power induction machine drives," in Proceedings of IECON 2016-42nd Annual Conference of the IEEE Industrial Electronics Society, Florence, 2016, pp. 5046-5051.

[21] M. Guan, B. Li, S. Zhou, Z. Xu and D. Xu, "Back-to-back hybrid modular multilevel converters for AC motor drive," in Proceedings of IECON 2017-43rd Annual Conference of the IEEE Industrial Electronics Society, Beijing, 2017, pp. 1822-1827.

[22] Z. Li, P. Wang, Z. Chu, H. Zhu, Y. Luo, and Y. Li, “An inner current suppressing method for modular multilevel converters," in IEEE Transactions on Power Electronics, vol. 28, no. 11, pp. 4873-4879, Nov. 2013.

[23] B. Li, R. Yang, D. Xu, G. Wang, W. Wang, and D. Xu, "Analysis of the phase-shifted carrier modulation for modular multilevel converters," in IEEE Transactions on Power Electronics, vol. 30, no. 1, pp. 297-310, Jan. 2015.

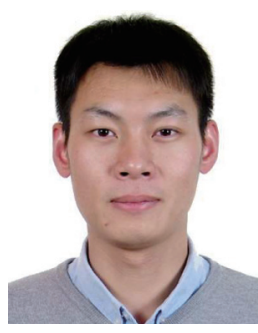

Binbin Li received the B.S., M.S., and Ph.D. degrees in electrical engineering from the Harbin Institute of Technology, Harbin, China, in 2010, 2012, and 2017, respectively. From 2015 to 2016, he was a Visiting Researcher with the Department of Electronic and Electrical Engineering, University of Strathclyde, Glasgow, U.K.. He is currently an Associate Professor with the Department of Electrical Engineering, Harbin Institute of Technology, and he has been selected in the Young Elite Scientists Sponsorship Program by

China Association for Science and Technology. His research interests include modular power converters, HVDC grid, and MVDC collection/distribution system.

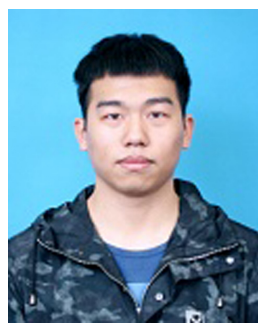

Junlin Hu received received the B.S. degree in electrical engineering from Shijiazhuang Tiedao University, Shijiazhuang, China, in 2019. He is currently pursuing the M.S. degree with the Harbin Institute of Technology, Harbin, China. His research interests include modular multilevel converter and power amplifier used in power hardware-in-the-loop.

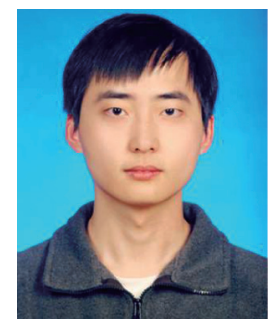

Shaoze Zhou was born in 1993. He received the B.S. degree in electrical engineering from Hohai University, Nanjing, China, in 2015. He is currently working toward the $\mathrm{Ph}$. D. degree at Harbin Institute of Technology, Harbin, China. His research interests include multilevel converters, motor drives and PWM techniques.

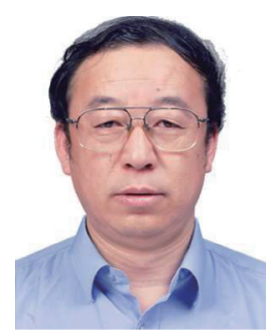

Dianguo $\mathrm{Xu}$ received the B.S. degree in control engineering from Harbin Engineering University, Harbin, China, in 1982, and the M.S. and Ph.D. degrees in electrical engineering from Harbin Institute of Technology (HIT), Harbin, China, in 1984 and 1989, respectively.

In 1984, he joined the Department of Electrical Engineering, HIT as an Assistant Professor. Since 1994, he has been a Professor in the Department of Electrical Engineering, HIT. He was the Dean of School of Electrical Engineering and Automation, HIT, from 2000 to 2010 . He is currently the Vice President of HIT. His research interests include renewable energy generation technology, multi-terminal HVDC system based on VSC, power quality mitigation, speed sensorless vector controlled motor drives, high performance servo system. He has published over 600 technical papers.

Prof. $\mathrm{Xu}$ is an Associate Editor of the IEEE Transactions on Industrial Electronics, IEEE Transactions on Power Electronics, and the IEEE Journal of Emerging and Selected Topics in Power Electronics. He also serves as Chairman of IEEE Harbin Section. 